\title{
O btenção e caracterização físico-química de concentrado protéico de folhas de mandioca
}

\author{
Carla R. P. A. Teo ${ }^{1}$, Sandra H. Prudencio ${ }^{2}$, Silvia R. M. Coelho $0^{3}$ Mauro S. Te ${ }^{4}$
}

\begin{abstract}
RESU MO
Este trabalho tem, como objetivo, comparar concentrados protéicos de folhas de mandioca produzidos por diferentes métodos e propor procedimento de obtenção com maior rendimento, conteúdo e recuperação protéica, menor teor de taninos e cor mais clara. Concentrados protéicos foram obtidos por coagulação ácida (pH $=5$ ), termocoagulação ácida $\left(\mathrm{pH}=4\right.$ e a temepratura 85 e $\left.50^{\circ} \mathrm{C}\right)$, coagulação em $30 \%$ etanol e termocoagulação $\left(60^{\circ} \mathrm{C}\right)$. Foram determinados nos concentrados protéicos e nas folhas umidade, proteína, taninos, luminosidade e tonalidade cromática. 0 s concentrados de maior rendimento, conteúdo protéico e cor mais clara (termocoagulação ácida pH 4 a $50{ }^{\circ} \mathrm{C}$ e coagulação $30 \%$ etanol) foram modificados. Após as modificações o concentrado obtido por coagulação em etanol apresentou 14,1\% de recuperação protéica, luminosidade de 73,8 e tonalidade cromática de $99,8^{\circ}$, não diferindo do concentrado produzido por termocoagulação ácida. 0 conteúdo de taninos foi de $0,4 \%$ nos dois concentrados. 0 s procedimentos de termocoagulação ácida em pH 4 e $50^{\circ} \mathrm{C}$ e coagulação em $30 \%$ etanol modificados, são apropriados para a produção de concentrado protéico de folhas de mandioca com grande recuperação protéica e cor clara.
\end{abstract}

Palavras-chave: ângulo hue, cor, imagens digitais, ingrediente alimentar, taninos

\section{Production and physicochemical characterization of cassava leaf protein concentrate}

\begin{abstract}
The aim of this work was to compare cassava leaf protein concentrates produced by different methods and to propose procedures with large yield, protein content and recovery, small tannin content and light color. Protein concentrates were obtained by acid coagulation ( $\mathrm{pH}=5$ ), acid thermo-coagulation ( $\mathrm{pH}=4$ at 85 and $50^{\circ} \mathrm{C}$ ), $30 \%$ ethanol coagulation and thermo-coagulation $\left(60^{\circ} \mathrm{C}\right)$. Moisture, protein and tannin contents, and brightness and chromatic tonality were determined in protein concentrates and dried milled leaves. The concentrates with the largest yields, protein contents and the lightest colors (acid thermo-coagulation pH 4 and $50{ }^{\circ} \mathrm{C}$ and $30 \%$ ethanol coagulation) were modified and, after the concentrate obtained by ethanol coagulation, presented a $14.1 \%$ protein recovery, a 73.8 brightness and $99.8^{\circ}$ chromatic tonality, not differing from the one produced by acid thermo-coagulation. The tannin content was $0.4 \%$ in both concentrates. The modified acid thermo-coagulation in $\mathrm{pH} 4$ and $50{ }^{\circ} \mathrm{C}$ and $30 \%$ ethanol coagulation procedures are correct for cassava leaf protein concentrate production with large protein recovery and light color.
\end{abstract}

Key words: hue angle, color, digital images, food ingredient, tannins

\footnotetext{
${ }^{1}$ Centro de Ciências da Saúde/U niversidade Comunitária Regional de Chapecó/U N OCHAPECÓ, Av. Senador Attilio Fontana, 591E, Bairro Efapi, CP 747, CEP 89990-000, Chapecó, SC. Fone: (49) 3321-8000. E-mail: carlateo@unochapeco.edu.br

2 UEL.TAM. Rodovia Celso Garcia Cid. PR-445, Km 380, Campus Universitário, CP 6001, CEP 86051-990, Londrina, PR .E-mail: sandrah@uel.br

3 PGEAGRI/CCET/U NIO ESTE. Rua Universitária, 2069, CEP 85819-110, Cascavel, PR. Fone: (45) 220-3250, CP 701. E-mail: srmcoelho@unioeste.br

${ }_{4}$ Rua Geriva, 58, Tropical, CEP 85807-260, Cascavel, PR. Fone: (45) 8817-3415. E-mail: teoms@bol.com.br
} 


\section{INTRODUÇÃO}

A produção brasileira de mandioca é de aproximadamente 26 milhões de toneladas (IBGE, 2007) e a parte aérea da planta apresenta alta produtividade, com o terço superior alcançando rendimentos de até $5,0 \mathrm{t} \mathrm{ha}^{-1}$, contendo folhas de elevado teor protéico, entre 21 e $30,0 \%$ em base seca, o que pode variar de acordo com o manejo da cultura (Carvalho et al., 1993; Pequeno et al., 2007; Silva et al., 2009). A proteína de folhas de mandioca apresenta balanço adequado em aminoácidos, deficiente apenas em metionina e triptofano, com excelentes valores de lisina (Awoyinka et al., 1995). Entretanto, taninos presentes nas folhas formam complexos insolúveis com proteínas (reduzindo sua digestibilidade) e conferem sabor adstringente e amargo (Fennema, 1996; Pinto, 2001), o que limita seu consumo direto. Taninos também podem formar complexos com enzimas da microbiota intestinal responsáveis por processos fermentativos e com enzimas digestivas, interferindo com a absorção de outros nutrientes, além das proteínas (Chiaradia et al., 1999).

Concentrados protéicos de folhas de mandioca apresentam, além de maior teor de proteína, diminuição do conteúdo de taninos e a introdução desses concentrados em alimentos à base de carboidratos é um recurso para o aproveitamento integral da planta com melhoria do valor nutritivo desses produtos (Ruiz-Carrera \& Franco-Gomes, 1986). Concentrados protéicos podem ser adicionados na formulação de alimentos em quantidades maiores que as folhas desidratadas moídas e vários métodos já foram desenvolvidos para concentrar esta proteína (Rosas-Romero \& Acosta,1986; Salgado \& Santos, 1986). Porém nos trabalhos realizados até o momento se empregaram variedades de mandioca e tempos de plantio diferentes, em condições climáticas diversas, impedindo a comparação dos procedimentos propostos. Além disso, os concentrados protéicos de folhas de mandioca apresentam coloração escura (Heinemann et al., 1998), o que pode prejudicar a qualidade dos alimentos aos quais forem adicionados.

A busca por novas fontes de proteína mobiliza pesquisadores do mundo todo, com o objetivo de substituir ou complementar as fontes de origem animal, de custo elevado (Awoyinka et al., 1995). A folhagem da mandioca submetida a tratamentos tecnológicos adequados surge como alternativa, uma vez que ainda não é convenientemente utilizada (Fioretto, 2001).

Assim, objetivou-se com este trabalho comparar concentrados protéicos de folhas de mandioca obtidos por diferentes procedimentos quanto às características de rendimento, conteúdo e recuperação protéica, teor de taninos e cor, e propor procedimentos para a produção deste potencial ingrediente alimentar.

\section{MATERIAL E MÉTODOS}

\section{Material e preparo da amostra}

Folhas do terço superior de mandioca (Manihot esculenta Crantz) da variedade Fécula Branca foram colhidas 180 (etapa I) e 240 (etapa II) dias após plantio de verão, na Região Oeste do Estado do Paraná.

Após a retirada dos pecíolos as folhas frescas foram lavadas em água destilada, secadas em estufa de circulação forçada de ar a $40{ }^{\circ} \mathrm{C}$, por $48 \mathrm{~h}$, moídas, peneiradas em peneira de 20 mesh, acondicionadas em frascos de vidro e guardadas ao abrigo de luz e umidade.

\section{Procedimentos de obtenção de concentrados proteícos na Etapa I}

Concentrados protéicos foram obtidos a partir das folhas desidratadas e moídas. As folhas foram submetidas a solubilização protéica, remoção da porção fibrosa, precipitação proteíca do filtrado, de acordo com cinco procedimentos citados na literatura:

Coagulação ácida (CA) - As folhas secas foram homogeneizadas em água destilada 1:20 (p/v) em pH 10, por 5 min, e se removeu a parte fibrosa por filtração com gase. No filtrado, o $\mathrm{pH}$ foi corrigido para 5 e o precipitado obtido foi separado por filtração (Rosas-Romero \& Acosta, 1986)

Termocoagulação ácida I (TCA I) - As folhas secas foram deixadas em repouso em solução de sulfito de sódio 5\%, na proporção de 1:10 (p/v) por $2 \mathrm{~h}$ e a parte fibrosa removida por filtração em gaze. A precipitação da proteína no filtrado foi realizada com pH 4 e aquecimento de $85{ }^{\circ} \mathrm{C}$. O precipitado obtido foi separado por filtração (Castellanos et al., 1994)

Termocoagulação (TC) As folhas secas foram homogeneizadas em água destilada na proporção 1:20 (p/v) por 5 min. A porção fibrosa foi retirada com filtração em gaze e o filtrado obtido foi aquecido a $60{ }^{\circ} \mathrm{C}$ para precipitação da proteína. Após o aquecimento o material ficou em repouso em temperatura ambiente, por $18 \mathrm{~h}$, e o precipitado separado por filtração (Salgado \& Santos, 1986)

Coagulação por etanol (CE) - As folhas secas foram homogeneizadas em água destilada na proporção 1:20 (p/v), durante $5 \mathrm{~min}$, e a porção fibrosa separada por filtração em gaze. Para a precipitação protéica, foram adicionados ao filtrado, $30 \%$ de etanol (v/v) e se separou o precipitado formado por filtração (Peluzio et al., 1998)

Termocoagulação ácida II (TCA II) - As folhas secas foram homogeneizadas em água destilada na proporção de 1:20 (p/v) em pH 7, por 5 min. A porção fibrosa foi separada por filtração com gaze e novamente homogeneizada com água destilada em $\mathrm{pH} 7$ e filtrada como descrito anteriormente. No filtrado obtido das duas extrações foi corrigido o $\mathrm{pH}$ para 4 e aquecido a $50{ }^{\circ} \mathrm{C}$ para precipitação da proteína e o precipitado foi filtrado (Salgado \& Santos, 1986)

Em todos os procedimentos descritos as folhas foram homogeneizadas utilizando-se liquidificador (WALITA Li$\mathrm{qFaz}^{\circledR}$ ) na velocidade máxima, a filtração final foi realizada em papel filtro Whatman ${ }^{\circledR} \mathrm{n}^{\mathrm{o}} 2$ e todos os precipitados obtidos foram secados em estufa de circulação de ar forçada a $60{ }^{\circ} \mathrm{C}$, por $24 \mathrm{~h}$.

\section{Procedimentos de obtenção de concentrados proteícos na etapa II}

Os dois procedimentos que resultaram em concentrados com maior rendimento, conteúdo e recuperação protéica e 
coloração mais clara, foram modificados e testados novamente com as folhas secas da etapa II:

Coagulação por etanol modificado $\left(\mathrm{CE}_{\mathrm{M}}\right)$ - As folhas secas foram homogeneizadas sob agitação com sulfito de sódio 5\% 1:10 (p/v) por $20 \mathrm{~min}$. Após este período ,se adicionou, nas folhas homogeneizadas com sulfito, se adicionou água na proporção de 1:10 (p/v) em relação ao peso inicial das folhas secas. O pH foi ajustado para 10 , seguido de nova homogeneização, durante $10 \mathrm{~min}$. A porção fibrosa foi separada por filtração com gaze e novamente homogeneizada. Nos filtrados obtidos foram adicionados $30 \%$ de etanol (v/v) e deixados em repouso a $4{ }^{\circ} \mathrm{C}$, por $18 \mathrm{~h}$, o precipitado obtido foi separado por filtração.

Termocoagulação ácida II modificada $\left(\mathrm{TCA} \mathrm{II}_{\mathrm{M}}\right)$ - As folhas secas foram homogeneizadas em água destilada na proporção de 1:20 (p/v) em $\mathrm{pH} \mathrm{7,} \mathrm{por} 5 \mathrm{~min}$. A porção fibrosa foi separada por filtração com gaze e novamente homogeneizada com água destilada em pH 7 e filtrada. Nos filtrados obtidos corrigiu-se o $\mathrm{pH}$ para 4 , na temperatura de $50{ }^{\circ} \mathrm{C}$ que foram deixados em repouso a $4{ }^{\circ} \mathrm{C}$ por $18 \mathrm{~h}$ e o precipitado obtido foi separado por filtração.

Em todos os procedimentos descritos as folhas foram homogeneizadas utilizando-se liquidificador (WALITA Li$\mathrm{qFaz}^{\circledR}$ ) na velocidade máxima, a filtração final foi realizada em papel filtro Whatman ${ }^{\circledR} \mathrm{n}^{\mathrm{o}} 2$ e todos os precipitados obtidos foram secados em estufa de circulação de ar forçada a $60{ }^{\circ} \mathrm{C}$, por $24 \mathrm{~h}$.

\section{Análises fisico-químicas realizadas nos concentrados obtidos nas etapas I e II (AOAC, 1990)}

Rendimento dos Concentrados - Foi determinado pelo cálculo da quantidade de concentrado em relação à de folhas desidratadas e moídas e expresso em porcentagem.

Conteúdo de Proteína e Umidade: O conteúdo de proteína nas folhas desidratadas moídas e nos concentrados foi determinado pelo método de Kjeldahl ( $\mathrm{N}$ x 6,25), de acordo com os procedimentos-padrão. A umidade foi determinada por secagem em estufa simples a $105^{\circ} \mathrm{C}$, até peso constante.

Recuperação de Proteína - Foi definida pelo cálculo da relação entre proteína no concentrado e proteína nas folhas desidratadas e moídas e expressa em porcentagem.

Conteúdo de Taninos: O conteúdo de taninos nas folhas desidratadas e moídas e nos concentrados foi determinado pelo método espectrofotométrico de Folin-Denis, segundo método 952.03 , a partir de um extrato metanólico das amostras (Pinto, 2001).

Cor - As folhas desidratadas moídas e os concentrados foram dispostos em vidros de relógio sobre fundo branco em uma câmara escura com sistema de iluminação para simular luz do dia (duas fontes D65, incidindo em ângulo de $45^{\circ}$ sobre a amostra) e imagens digitais obtidas utilizando-se câmera fotográfica Sony® (Mavica/MVC-FD75, lente de $5,5 \mathrm{~mm}$ e abertura de diafragma de $50,0 \%$ ) posicionada perpendicularmente à amostra a uma distância de $20 \mathrm{~cm}$. As imagens digitais em extensão bmp foram convertidas para valores RGB médios pelo programa SH2.0 (Sachs, 2002) e, através do programa MSPAINT ${ }^{\circledR} 4.9$, obtiveram-se as cores médias dos concentrados. Os valores RGB foram converti- dos para o sistema CIELAB, pelo programa Munsell Conversion 6.41 (COlorpro, 2004), fornecendo os valores de L*, $\mathrm{a}^{*} \mathrm{e} \mathrm{b}$. O parâmetro $\mathrm{H}^{*}$ (tonalidade cromática) foi calculado segundo Camelo \& Gómez (2004).

\section{Delineamento experimental e análise estatística}

$\mathrm{O}$ experimento foi conduzido em delineamento inteiramente casualizado com três repetições compostas de três determinações cada uma. Os resultados foram testados por análise de variância e pelo teste de Tukey para comparação de médias, utilizando-se nível de significância de 5,0\%.

\section{RESULTADOS E DISCUSSÃO}

Os conteúdos de umidade, proteína e taninos das folhas de mandioca desidratadas e moídas (Tabela 1) foram obtidos para balizar a avaliação dos concentrados protéicos. $\mathrm{O}$ menor conteúdo de proteína e o maior teor de taninos nas folhas na etapa II eram esperados devido ao aumento do tempo de plantio (Gomez et al., 1985; Carvalho et al., 1993).

Tabela 1. U midade (\%), proteína (\%) etaninos (g deácido tânico por $100 \mathrm{~g}$ ) nasfolhas de mandioca da variedade fécula branca desidratadas e moídas ${ }^{1}$

\begin{tabular}{lccc}
\hline & $\begin{array}{c}\text { Umidade } \\
(\%)\end{array}$ & $\begin{array}{c}\text { Proteína } \\
(\%)^{2,3}\end{array}$ & Tanino $^{3}$ \\
$\begin{array}{l}\text { Etapa I (folhas colhidas 180 dias } \\
\begin{array}{l}\text { após plantio) } \\
\text { Etapa II (folhas colhidas 240 dias } \\
\text { após plantio) }\end{array}\end{array} \quad 9,8 \pm 0,1$ & $38,5 \pm 0,5$ & $0,6 \pm 0,1$ \\
\hline
\end{tabular}

${ }^{1}$ Valores médios de três determinações \pm desvio padrão, com resultados expressos em g por $100 \mathrm{~g} ;{ }^{2} \mathrm{~N} \times 6,25 ;{ }^{3}$ Resultados expressos em base seca

\section{Concentrados protéicos na etapa I}

$O$ rendimento de concentrado a partir das folhas desidratadas (Tabela 2) pelo procedimento TCA II, foi o que apresentou o maior resultado, diferindo dos demais e seguido de CE, CA e TC, com TCA I apresentando o menor rendimento, também diferente de todos os outros. O maior rendimento de TCA II pode ser explicado pela dupla homogeneização da amostra neste procedimento. Quanto ao método TCA I, o rendimento inferior aos demais foi devido, provavelmente, à ausência de uma etapa de homogeneização da amostra com menor solubilização da proteína das folhas, que

Tabela 2. Rendimento, umidade, conteúdo e recuperação protéica e teor de taninos dos concentrados protéicos na etapa $\left.\right|^{1}$

\begin{tabular}{lccccc}
\hline Procedimento & $\begin{array}{c}\text { Rendimento } \\
\text { dos } \\
\text { Concentrados } \\
(\%)\end{array}$ & $\begin{array}{c}\text { Umidade } \\
(\%)\end{array}$ & $\begin{array}{c}\text { Conteúdo } \\
\text { Proteíco } \\
(\%)\end{array}$ & $\begin{array}{c}\text { Recuperação } \\
\text { de Proteína } \\
(\%)\end{array}$ & $\begin{array}{c}\text { Taninos } \\
\text { (g de ácido } \\
\text { tânico/100 g } \\
\text { de }\end{array}$ \\
CA & $14,0 \pm 2,1 \mathrm{c}$ & $5,4 \pm 0,1 \mathrm{~b}$ & $57,2 \pm 2,6 \mathrm{~b}$ & $8,0 \pm 0,9 \mathrm{c}$ & $0,4 \pm 0,1 \mathrm{a}$ \\
concentrado)
\end{tabular}

${ }^{1}$ Resultados expressos em base seca como valores médios de três repetições com três determinações cada uma \pm desvio padrão; ${ }^{2} \mathrm{~N} \times 6,25$

Médias acompanhadas de letras diferentes diferem significativamente $(p \leq 0,05)$ 
foram apenas maceradas, o que resultou também em um conteúdo protéico menor.

Observaram-se diferenças quanto ao conteúdo protéico (Tabela 2) entre os procedimentos testados, exceto entre CA e TC. $\mathrm{O}$ maior conteúdo no concentrado $\mathrm{CE}$ indica que a operação de concentração da proteína por solvente orgânico resultou em menor perda da proteína presente no extrato bruto. Portanto, o ambiente ácido mais severo, com $\mathrm{pH}=4,0$, independentemente da temperatura fornecida $\left(85^{\circ} \mathrm{C}\right.$ para TCA I e $50{ }^{\circ} \mathrm{C}$ para TCA II), não ofereceu vantagens na precipitação das proteínas em relação ao emprego de etanol (CE), assim como os processos a temperatura de $60{ }^{\circ} \mathrm{C}(\mathrm{TC})$ ou com o $\mathrm{pH}=5,0 \mathrm{sem}$ aquecimento (CA). Quanto ao $\mathrm{pH}$, pode ser inferido, neste caso, que o ponto isoelétrico da proteína de folha de mandioca está situado mais próximo de 5,0, uma vez que nesse ponto ocorre maior insolubilização protéica.

Outros autores, estudando o conteúdo de concentrados de proteína obtidos por diferentes métodos, encontraram resultados inferiores aos deste estudo. Rosas-Romero \& Acosta (1986) citam 46,8\% de proteína em concentrado obtido de folhas de mandioca pelo método CA; Castellanos et al. (1994) relatam um teor de proteína de $42,92 \%$ em concentrado obtido pelo método TCA I e Peluzio et al. (1998) obtiveram $51,97 \%$ de proteína em um concentrado produzido pelo método CE. Salgado \& Santos (1986) relatam 32,5 a $37,1 \%$ de proteína em concentrados obtidos pelo método TC e 25,1 a 27,9\% pelo método TCA II. Os maiores conteúdos protéicos obtidos neste trabalho com os mesmos procedimentos podem ser devidos à quantidade superior de água utilizada para homogeneização da amostra, com maior interação entre solvente e amostra, menor perda da mesma e maior solubilização das proteínas. Os concentrados TCA II e CE também apresentaram os maiores percentuais de recuperação da proteína contida nas folhas desidratadas (Tabela 2), de 14,1 e $11,0 \%$, respectivamente.

Os concentrados protéicos obtidos pelos diferentes procedimentos apresentaram conteúdos de tanino semelhantes (Tabela 2), tendo-se observado reduções de 37,70\% a 50,82\% em relação às folhas desidratadas, em conformidade com Vilhena et al. (1996), que mencionam redução de 50,0\%. Por outro lado, Rosas Romero \& Acosta (1986) encontraram um conteúdo de tanino em concentrado protéico obtido pelo método CA a partir de folhas frescas de mandioca, mais elevado, de 2,09\%, indicando que a secagem das folhas e sua trituração antes das operações de concentração da proteína contribuíram para a redução do conteúdo desses compostos (Padmaja, 1989). Na fase de extração da proteína a homogeneização da farinha de folhas em água também influenciou a redução dos taninos, uma vez que referidos compostos são hidrossolúveis, principalmente sob agitação (Lima et al., 2004). No caso do método TCA I e apesar da ausência de agitação, a redução dos taninos se deveu, provavelmente, à maceração em sulfito de sódio (Chiaradia et al., 1999).

Não existe limitação para o conteúdo de taninos em alimentos e, além disso, está bem descrito o papel antioxidante benéfico desses e de outros compostos fenólicos na dieta (Valverde et al., 2000). Trabalhos realizados com erva mate citam teores de taninos entre 0,5 e 0,6\% (Donaduzzi \& Cardo- zo, 2003). Em ervilhas e vagens referidos compostos são encontrados na ordem de 2,0\% (Valverde et al., 2000) e em feijão-preto foram encontrados conteúdos variando entre 0,4 e 2,0\% (Corrêa et al., 2002; Lima et al., 2004)]. Considerando essas referências, os teores de tanino dos concentrados protéicos são compatíveis com os valores normalmente observados em outros alimentos e bebidas de consumo usual.

As operações empregadas na concentração da proteína implicam em reações químicas diversas que podem resultar em características de cor mais ou menos desejáveis nos concentrados obtidos, porém as referências a esta característica de qualidade de concentrados protéicos de folhas de mandioca são escassas. Apenas Heinemann et al. (1998) mencionam que a cor do concentrado obtido por fermentação é verde-musgo e Sgarbieri (1996) cita que concentrados protéicos de folhas apresentam coloração verde escuro; desta forma e visando à utilização do concentrado protéico de folhas de mandioca como ingrediente alimentar e se considerando que a cor escura pode prejudicar a aceitação de determinados alimentos pelo consumidor, é importante o estudo desta característica.

É possível identificar visualmente, através da cor média (Figura 1), as diferenças de cor entre os concentrados e entre estes e as folhas desidratadas moídas, todos variando em tons de verde.

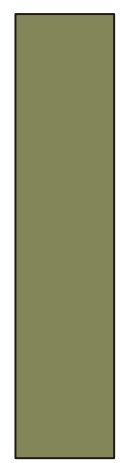

Folhas

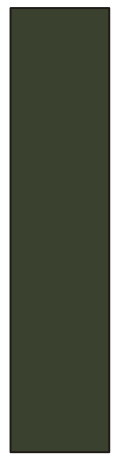

CA

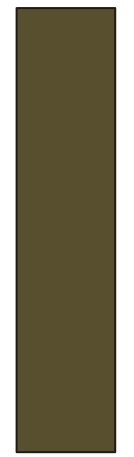

TCA I

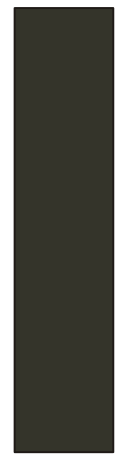

TC

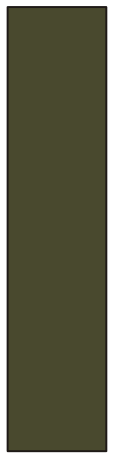

CE

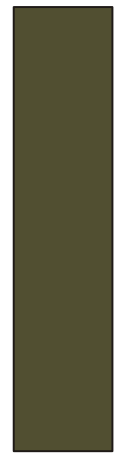

TCA II
Figura 1. Cor média das folhas de mandioca desidratadas moídas e dos concentrados protéicos na etapa I

Os concentrados obtidos pelos procedimentos TCA I, TCA II e CE não diferiram quanto à luminosidade, apresentando os maiores valores de L* (Tabela 3 ), ou seja, possuíam as cores mais claras, uma vez que $\mathrm{L}^{*}$ varia de zero (preto) a cem (branco) (Camelo \& Gomes, 2004). As folhas desidratadas moídas apresentaram $\mathrm{L}^{*}$ superior aos dos concentrados e cor mais clara; entretanto, as folhas apresentam o inconveniente de não poderem ser adicionadas a alimentos (como ingrediente) na mesma quantidade que os concentrados.

Os valores de $\mathrm{H}^{*}$ (Tabela 3 ) situam as colorações dos concentrados e das folhas desidratadas no quadrante compreendido entre 90 e $180^{\circ}$ no espaço físico de cor do sistema CIELAB, composto de maiores intensidades de verde e amarelo (HunterLab, 2004). Para este parâmetro, apenas o concentrado TCA I diferiu dos demais, mostrando uma coloração 
Tabela 3. Luminosidade $\left(\mathrm{L}^{*}\right)$ e tonalidade cromática $\left(\mathrm{H}^{*}\right)$ das folhas desidratadas moídas e dos concentrados protéicos na etapa ${ }^{1}$

\begin{tabular}{lcc}
\hline Material & \multicolumn{1}{c}{ L* $^{*}$} & H*2 $^{*}$ \\
Folhas Desidratadas & $56,0 \pm 0,2 \mathrm{a}$ & $107,9 \pm 1,1 \mathrm{a}$ \\
CA & $25,5 \pm 1,2 \mathrm{C}$ & $106,0 \pm 2,6 \mathrm{ab}$ \\
TCA I & $33,1 \pm 1,2 \mathrm{~b}$ & $94,9 \pm 1,8 \mathrm{C}$ \\
TC & $18,9 \pm 3,1 \mathrm{~d}$ & $100,9 \pm 2,6 \mathrm{~b}$ \\
CE & $29,3 \pm 1,8 \mathrm{bc}$ & $101,9 \pm 1,8 \mathrm{~b}$ \\
TCA II & $33,4 \pm 0,9 \mathrm{~b}$ & $101,1 \pm 0,5 \mathrm{~b}$ \\
\hline
\end{tabular}

${ }^{1}$ Valores médios de três repetições com três determinações cada uma \pm desvio padrão; 2 Resultados expressos em graus

Médias acompanhadas de letras diferentes diferem significativamente $(p \leq 0,05)$

plotada no plano equatorial da esfera de cor em um ângulo menor, mais próximo de $90^{\circ}$, o qual representa, teoricamente, o amarelo puro (Ferreira \& Minami, 2000). Desta forma, quanto menor o valor de $\mathrm{H}^{*}$ neste quadrante, mais clara a cor correspondente; portanto, apesar de TCA I, TCA II e CE não diferirem quanto a $\mathrm{L}^{*}$, a aparência de cor mais clara de TCA I é dada em função de seu menor valor de $\mathrm{H}^{*}$ e pode ser explicada pela utilização de sulfito de sódio na fase de extração da proteína, já que esta substância inibe irreversivelmente a enzima polifenoloxidase, além de interagir com intermediários precursores do pigmento escuro (formando sulfoquinonas) e de atuar como agente redutor prevenindo, através desses mecanismos, a oxidação dos taninos e, consequentemente, o escurecimento (Araújo, 2006). A cor mais clara das folhas desidratadas em relação aos concentrados, apesar do maior valor de $\mathrm{H}^{*}$, é devida ao maior valor de $\mathrm{L}^{*}$.

\section{Concentrados protéicos na etapa II}

Nesta etapa foram propostas e testadas modificações nos procedimentos utilizados na etapa I, que resultaram em concentrados protéicos de maior rendimento, conteúdo e recuperação protéica, além de cor mais clara. As modificações visaram incrementar os resultados obtidos na etapa I, tendo sido selecionados os procedimentos TCA II e CE. Devido à cor média mais clara do concentrado TCA I, creditada ao emprego de sulfito de sódio, esta substância foi associada às modificações e os procedimentos modificados foram denominados TCA $\mathrm{II}_{\mathrm{M}}$ e $\mathrm{CE}_{\mathrm{M}}$.

Não se observaram diferenças entre os dois procedimentos modificados quanto ao rendimento de concentrado (Tabela 4), tendo os mesmos apresentado rendimento superior ao dos concentrados na etapa I.

Tabela 4. Rendimento, umidade, conteúdo e recuperação protéica e teor de tanino dos concentrados protéicos, antes e após modificações ${ }^{1}$

\begin{tabular}{cccccc}
\hline Procedimento & $\begin{array}{c}\text { Rendimento } \\
\text { dos } \\
\text { Concentrados } \\
(\%)\end{array}$ & $\begin{array}{c}\text { Umidade } \\
(\%)\end{array}$ & $\begin{array}{c}\text { Conteúdo } \\
\text { Protéico } \\
(\%)^{2}\end{array}$ & $\begin{array}{c}\text { Recuperação } \\
\text { de Proteína } \\
(\%)\end{array}$ & $\begin{array}{c}\text { Taninos } \\
\text { (g de ácido } \\
\text { tânico/100 g } \\
\text { de }\end{array}$ \\
concentrado)
\end{tabular}

${ }^{1}$ Resultados expressos em base seca como valores médios de três repetições com três determinações cada \pm desvio padrão; ${ }^{2} \mathrm{~N}$ x 6,25

Médias acompanhadas por letras diferentes diferem significativamente $(p \leq 0,05)$
Previa-se o maior rendimento, uma vez que foi empregada dupla homogeneização da amostra, tratamento repetido com as fibras residuais, permitindo maior interação da mesma com o solvente. Esta modificação também resultou em maior solubilização das proteínas das folhas desidratadas, o que refletiu em maior teor protéico dos concentrados e maior recuperação da proteína das folhas desidratadas do que na etapa anterior, apesar do menor conteúdo de proteína nas folhas nesta etapa. A recuperação protéica não diferiu entre os dois procedimentos modificados e foi, respectivamente, de 18,5 e 18,1\% para $\mathrm{CE}_{\mathrm{M}}$ e $\mathrm{TCA}_{\mathrm{II}}$. O conteúdo de proteína de $\mathrm{CE}_{\mathrm{M}}$ foi maior que o de $\mathrm{TCA} \mathrm{II}_{\mathrm{M}}$, confirmando a menor perda da proteína presente no extrato bruto pelo emprego de concentração protéica por solvente orgânico.

Quanto ao conteúdo de taninos, não houve diferença entre os concentrados protéicos obtidos pelos procedimentos modificados (Tabela 4), ou entre os concentrados nas duas etapas. Entretanto, se constataram reduções de 68,91 e $70,56 \%$ em relação aos taninos das folhas desidratadas nos concentrados obtidos na etapa II, as quais foram superiores às reduções observadas na etapa I. Esta diferença ocorreu em virtude, provavelmente, de uma solubilização maior, com posterior remoção dos taninos das folhas desidratadas pela agitação em sulfito de sódio e homogeneização em água. Referidos resultados condizem com os relatos de outros trabalhos (Vilhena et al., 1996; Corrêa et al., 2004). Lima et al. (2004) estudando a remoção de taninos de brotos de feijão-mungo observaram que a água foi tão eficiente quanto o etanol na remoção.

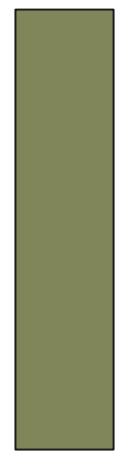

Folhas Etapa I

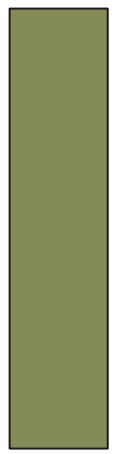

Folhas Etapa II

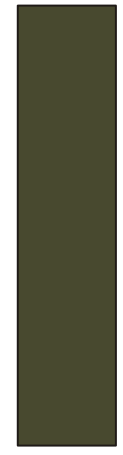

$\mathrm{CE}$

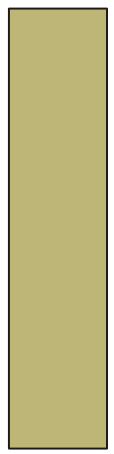

CE M

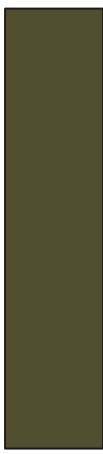

TCA II

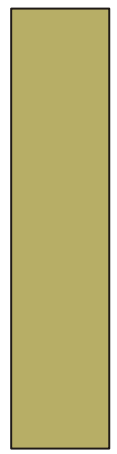

TCA II M
Figura 2. Cor média das folhas de mandioca desidratadas moídas nas etapas | e I| e dos concentrados protéicos, antes e após modificações

A cor média dos concentrados da etapa II (Figura 2) foi mais clara que a daqueles da etapa I e esta diferença foi confirmada pelos valores do parâmetro $L^{*}$, iguais para TCA $\mathrm{II}_{\mathrm{M}}$ e $\mathrm{CE}_{\mathrm{M}}$ e superiores aos observados para todos os procedimentos na etapa I (Tabela 5). A cor média das folhas desidratadas não diferiu entre as duas etapas e, na etapa II, os concentrados foram mais claros que os folhas.

As tonalidades cromáticas dos concentrados modificados foram iguais e apenas $\mathrm{TCA}_{\mathrm{II}}$ diferiu quanto a $\mathrm{H}^{*}$ dos concentrados da etapa I. Portanto, a diferença observada na cor média desses concentrados quando comparados com os da 
Tabela 5. Luminosidade $\left(\mathrm{L}^{*}\right)$ e tonalidade cromática $\left(\mathrm{H}^{*}\right)$ das folhas desidratadas moídas na etapa II e dos concentrados protéicos antes e após modificações ${ }^{1}$

\begin{tabular}{ccc}
\hline Procedimento & L* & $\mathbf{H}^{* 2}$ \\
Folhas desidratadas & $57,5 \pm 0,4 \mathrm{~b}$ & $107,6 \pm 0,2 \mathrm{a}$ \\
CE & $29,3 \pm 1,8 \mathrm{~d}$ & $101,9 \pm 1,8 \mathrm{~b}$ \\
TCA II & $33,4 \pm 0,9 \mathrm{C}$ & $101,1 \pm 0,5 \mathrm{~b}$ \\
CEM & $73,8 \pm 1,2 \mathrm{a}$ & $99,8 \pm 0,5 \mathrm{bc}$ \\
TCA IIM & $70,8 \pm 0,4 \mathrm{a}$ & $98,3 \pm 0,6 \mathrm{c}$ \\
\hline
\end{tabular}

${ }^{1}$ Valores médios de três repetições com três determinações cada uma \pm desvio padrão; ${ }^{2}$ Resultados expressos em graus

Médias acompanhadas de letras diferentes diferem significativamente $(p \leq 0,05)$

etapa I, foi devida aos maiores valores de L* obtidos após as modificações dos procedimentos de obtenção. A cor mais clara dos concentrados na etapa II resultou do uso de sulfito de sódio, procedimento ausente em TCA II e CE e cuja eficiência na remoção de taninos e na prevenção do escurecimento foi aumentada pelo emprego de agitação (Araújo, 2006).

\section{CONCLUSÕES}

1. Entre os procedimentos descritos na literatura, TCA II e CE resultam em concentrados com maior conteúdo protéico, maior rendimento, maior recuperação de proteína e cor mais clara.

2. A introdução de sulfito de sódio e de dupla homogeneização da amostra nesses procedimentos, é eficiente para incrementar tais características e para aumentar a remoção de taninos, resultando em potencial ingrediente mais adequado para emprego em alimentos.

\section{LITERATURA CITADA}

AOAC - Association of Official Analytical Chemists. Official methods of analysis, $15^{\text {th }}$ edition. Washington: AOAC, 1990.

Araújo, J. M. A. Química de alimentos - teoria e prática, 3.ed. Viçosa: UFV, 2006. 478p.

Awoyinka, A. F.; Abegunde, A. F.; Adewusi, S. R. A. Nutrient content of young cassava leaves and assessment of their acceptance as a green vegetable in Nigeria. Plant Foods for Human Nutrition, v.47, p.21-28, 1995.

Camelo, A. F. L.; Gómez, P. A. Comparison of color indexes for tomato ripening. Horticultura Brasileira, v.22, n.3, p.534-537, 2004.

Carvalho, V. D.; Chagas, S. J. R.; Botrel, N.; Juste Júnior, E. S. G. Teores de proteína na parte aérea de cultivares de mandioca em diferentes épocas de colheita. Revista Brasileira de Mandioca, v.12, n.1/2, p.13-20, 1993.

Castellanos, R.; Altamirano, S. B.; Moretti, R. H. Nutritional characteristics of cassava (Manihot esculenta Crantz) leaf protein concentrates obtained by ultrafiltration and acidic thermocoagulation. Plant Foods for Human Nutrition, v.45, p.357-363, 1994.
Chiaradia, A. C. N.; Costa, N. M. B.; Gomes, J. C. Retirada do tegumento e extração dos pigmentos na qualidade protéica do feijão-preto. Revista de Nutrição, v.12, n.2, p.31-136, 1999.

Colorpro. Munsell Conversion versão 6.41. http://www.colorpro. com/info/software/munsell.htm. 31 Out. 2004.

Corrêa, A. D.; Santos, C. D.; Natividade, M. A. E.; Abreu, C. M. P.; Xisto, A. L. R. P.; Carvalho, V. D. Farinha de mandioca I - efeito da secagem das folhas sobre a atividade da linamarase. Ciência e Agrotecnologia, v.26, n.2, p.368-374, 2002.

Corrêa, A. D.; Santos, S. R.; Abreu, C. M. P.; Jokl, L.; Santos, C. D. Remoção de polifenóis da farinha de folhas de mandioca. Ciência e Tecnologia de Alimentos, v.24, n.2, p.159-164, 2004.

Donaduzzi, C. M.; Cardozo, E. L. Variação nos teores de polifenóis totais e taninos em dezesseis progênies de erva-mate (Ilex paraguariensis St. Hill.) cultivadas em três municípios do Paraná. Arquivos de Ciências da Saúde da Unipar, v.7, n.2, p.129-133, 2003.

Fennema, O. Food chemistry, 3. edition. New York: Marcel Dekker, 1996.1069p.

Ferreira, M. D.; Minami, K. Qualidade de bulbos de cebola em consequiência de tratamentos pré-colheita. Scientia Agricola, v.57, n.4, p.693-701, 2000.

Fioretto, A. M. C. Culturas de tuberoses amiláceas latinoamericanas - Manejo, uso e tratamento de subprodutos da industrialização da mandioca v.IV. São Paulo: Fundação Cargill, 2001. 711p.

Gomez, G.; Valdivieso, M.; Noma, A. T. The influence of cultivar and plant age on the chemical composition of field-grown cassava leaves and roots. Plant Foods for Human Nutrition, v.35, p.109-119, 1985.

Heinemann, R. B.; Costa, N. M. B.; Cruz, R.; Pirozi, M. R. Valor nutricional de farinha de trigo combinada com concentrado protéico de folha de mandioca. Revista de Nutrição, v.11, n.1, p.51-57, 1998.

HunterLab. Hunter L, a, b versus CIE 1976 1*a*b*. http:// www.hunterlab.com/ cs_publications.phpbr. 11 Nov. 2004.

IBGE - Instituto Brasileiro de Geografia e Estatística. Estatísticas. http://www.ibge.gov.br. 10 Mar. 2007.

Lima, V. L. A. G.; Melo, E. A.; Maciel, M. I. S.; Silva, G. S. B.; Lima, D. E. S. Fenólicos totais e atividade antioxidante do extrato aquoso de broto de feijão-mungo (Vigna radiata L.). Revista de Nutrição, v.17, n.1, p.53-57, 2004.

Padmaja, G. Evaluation of techniques to reduce assayable tannin and cyanide in cassava leaves. Journal of Agricultural and Food Chemistry, v.37, p.712-716, 1989.

Peluzio, M. C. G.; Miranda, L. C. G.; Moraes, G. H. K.; Peluzio, L. E. Avaliação da qualidade nutricional da proteína da folha de mandioca combinada com a caseína pela reação de plasteína. Archivos Latinoamericanos de Nutrición, v.48, n.4, p.311-315, 1998.

Pequeno, M.; Vidigal Filho, P. S.; Tormena, C.; Kvitschal, M. V.; Manzotti, M. Efeito do sistema de preparo do solo sobre características agronômicas da mandioca (Manihot esculenta Crantz). Revista Brasileira de Engenharia Agrícola e Ambiental, v.11, n.3, p.476-481, 2007.

Pinto, N. A. V. D. Avaliação de fatores antinutricionais das folhas de taioba (Xanthosoma sagittifolium Schoot). Ciência e Agrotecnologia, v.25, n.3, p.601-604, 2001. 
Rosas-Romero, A. J.; Acosta, X. The biological quality of a cassava leaf protein concentrate. Acta Científica Venezolana, v.37, p.441-444, 1986.

Ruiz-Carrera, V; Franco-Gomes, M. J. Pastas alimentícias suplementadas con concentrado proteínico de hojas de yuca (Manihot esculenta Crantz). Tecnologia Alimentícia, v.20, n.2, p.10-14, 1986.

Sachs, L. G. Parâmetros agronômicos e tecnológicos para produção e emprego de farinha desengordura de girassol (Helianthus annuus L. EMBRAPA BR-122v2000) em sistema alimentar. Londrina: UEL, 2002. 155p. Tese Doutorado

Salgado, J. M.; Santos, A. C. Estudo do concentrado protéico da folha de mandioca: obtenção, análises químicas e suplementação com aminoácidos. Archivos Latinoamericanos de Nutrición, v.36, n.3, p.483-494, 1986.
Sgarbieri, V. Proteínas em alimentos protéicos, São Paulo: Varela, 1996. 517p.

Silva, A. F.; Santana, L. M.; França, C. R. R. S.; Magalhães, C. A. S.; Araújo, C. R.; Azevedo, S. G. Produção de diferentes variedades de mandioca em sistema agroecológico. Revista Brasileira de Engenharia Agrícola e Ambiental, v.13, n.1, p.33-38, 2009.

Valverde, M. I.; Periago, M. J.; Ros, G. Significado nutricional de los compuestos fenolicos de la dieta. Archivos Latinoamericanos de Nutrición, v.50, n.1, p.15-25, 1986.2000.

Vilhena, M. F. S.; Ribeiro, E.; Cozzolino, S. M. F.; Meire, E.; Ramírez, E. Effecto de la extrusion sobre el valor nutritivo de la proteína de las hojas de yuca (Manihot esculenta Crantz). Alimentaria, v.5, p.85-90, 1996. 